\title{
Efeito do ultra-som na prevenção da hérnia incisional mediana no rato ${ }^{1}$
}

\author{
Prevention of median incisional hernia in the rat by ultrasonic therapy
}

\author{
Renato Miranda de Melo², Cibele Marli Cação Paiva Gouvêa ${ }^{3}$, Alcino Lázaro da Silva ${ }^{4}$ \\ 1. Trabalho desenvolvido no Departamento de Ciências Biológicas da Escola de Farmácia e Odontologia de Alfenas, \\ Centro Universitário Federal - EFOA/CEUFE e no Curso de Pós-Graduação em Cirurgia da Universidade Federal de \\ Minas Gerais (UFMG). \\ 2. Doutorando pelo Programa de Pós-Graduação em Cirurgia da FM-UFMG. Belo Horizonte - MG. \\ 3. Professora Adjunta do DCB da EFOA/CEUFE. Alfenas - MG. \\ 4. Professor Titular de Cirurgia do Aparelho Digestivo da FM-UFMG. Belo Horizonte - MG.
}

\section{RESUMO}

Objetivo: Investigar se o ultra-som é capaz de evitar o aparecimento da hérnia incisional (HI), uma vez que o seu tratamento ainda é um problema não resolvido. Métodos: Induziu-se a HI, por secção da linha alba, em 20 ratos Wistar, distribuídos em dois grupos: um recebeu a aplicação do ultra-som, na área operada, por 14 dias e o outro por 28 dias, cada qual com seu subgrupo controle (não tratado). Utilizou-se aparelho com cabeçote reduzido, modo pulsado (1:5), freqüência de 3,0MHz e intensidade de 0,5W/cm², durante $5 \mathrm{~min} /$ dia, iniciando-se as aplicações no primeiro dia de pós-operatório. Ao final, mediu-se o diâmetro transverso do anel herniário ou da largura da cicatriz na linha alba, definindo-se a HI quando esses valores ultrapassassem $2 \mathrm{~mm}$. A densidade de vasos sangüíneos, de fibroblastos e de fibras colágenas, nessas estruturas, foi estudada à microscopia óptica. As médias e o erro padrão foram submetidos à análise de variância (ANOVA) e ao teste de comparação múltipla de Tukey-Kramer. Resultados: Dos animais tratados com o ultra-som, $60 \%$ não desenvolveram a HI e, nos restantes, o anel herniário foi menor do que os não tratados ( $\mathrm{p}<0,0001)$. A densidade de vasos sangüíneos $(\mathrm{p}=0,0031)$, de fibroblastos $(\mathrm{p}<0,0001)$ e de fibras colágenas $(\mathrm{p}=0,0015)$ também foi maior, em relação aos controles. Não houve diferença significante nesses parâmetros, comparandose os dois períodos de tratamento. Conclusão: O ultra-som evitou o aparecimento da $\mathrm{HI}$ ou reduziu o seu tamanho, quando aplicado por 14 dias no pós-operatórios.

Descritores: Hérnia ventral. Abdome. Ultra-som. Cicatrização de feridas. Ratos.

\begin{abstract}
Purpose: To investigate if ultrasonic therapy is effective in avoidance of incisional hernia (IH), once the ideal technique for repair of $\mathrm{IH}$ is still a non-solved problem, in despite of prostheses usage. Methods: IH was created by linea alba opening over 20 male Wistar rats, distributed in two groups: one group received the ultrasound, over the wound, during 14 days ( 5 animals) and the other for 28 days ( 5 animals), each one with the same number of animals as controls. The ultrasound was applied using a small probe, 1:5 pulse mode, 3.0MHz frequency and $0.5 \mathrm{~W} / \mathrm{cm}^{2}$ intensity, for 5 minutes daily, from the first postoperative day. The width of the linea alba scar or the hernia ring was measured at the end of every period. The IH was defined when these openings were over $2 \mathrm{~mm}$ wide. Some specimens from hernia sac or linea alba scar were obtained for vessels, fibroblasts, and colagen fibers density. Standard deviation and medians were obtained by variation analysis and Tukey-Kramer multi-comparison test. Results: The ultrasound group showed a linea alba scar in 60\%. The other $40 \%$ presented the hernia ring smaller than the non treated group ( $<<0.0001)$. The ultrasound
\end{abstract}


increased density of blood vessels ( $p=0,0031)$, fibroblasts $(p<0,0001)$, and collagen fibers $(p=0,0015)$. There was no difference between the two treated groups. Conclusion: The ultrasound avoided the IH to appear or reduced its width. Fourteen days of treatment were sufficient for this purpose.

Key words: Ventral hernia. Abdome. Ultrasonic. Wound healing. Rats.

\section{Introdução}

A laparotomia mediana ainda é uma das vias de acesso mais praticadas, sobretudo nos casos de urgência, por ser de execução simples e rápida. A hérnia incisional (HI) figura entre as complicações tardias dessas feridas, acometendo até um quinto dos pacientes operados. Ela ocorre pelo afastamento progressivo das bordas músculo-aponeuróticas incisadas, mantendo-se íntegros a pele, as fáscias musculares e o peritônio parietal que, juntos, compõem o saco herniário. Para dentro deste, escapa o conteúdo abdominal, provocando o abaulamento da cicatriz. Em geral, é detectada no primeiro ano pós-operatório, mesmo depois da aparente consolidação da ferida abdominal. Além de desconfortável e antiestética, predispõe à insuficiência respiratória, à obstrução intestinal e às distrofias ou mesmo às úlceras de pele.

A utilização de próteses (telas) representou um avanço sem precedentes no reparo da HI, por diminuir a taxa de recidiva, mas com elas também surgiram complicações, muitas delas graves e de difícil tratamento, como as fístulas intestinais e a dor crônica ${ }^{1}$. Apesar da técnica de laparorrafia em bloco ter diminuído a sua incidência ${ }^{2,3}$, a cirurgia da HI continua um problema não resolvido, mesmo com o uso dessas próteses, afastando os pacientes de suas atividades habituais. Justifica-se, portanto, o estudo mais pormenorizado dos fatores envolvidos na etiopatogênese, no tratamento e também na prevenção da HI.

A terapia ultra-sônica tem se mostrado efetiva no tratamento das lesões músculo-tendíneas ${ }^{4,5}$, com efeitos colaterais desprezíveis, se obedecidos os critérios para o manejo adequado desse equipamento ${ }^{6}$. Uma vez que a HI é, basicamente, um defeito no estrato músculo-aponeurótico da parede abdominal, é possível que o ultra-som, agindo neste estrato, possa evitar o aparecimento dessa complicação. O presente trabalho tem como objetivos induzir a hérnia incisional mediana, por secção da linha alba, e verificar a capacidade do ultra- som em prevenir a sua formação, estudando os aspectos macro e microscópicos do defeito provocado no plano músculo-aponeurótico da parede abdominal do rato.

\section{Métodos}

Foram utilizados 20 ratos (Rattus norvegicus albinus) Wistar, machos, adultos, pesando $270 \pm 20 \mathrm{~g}$, obtidos do Biotério da Escola de Farmácia e Odontologia deAlfenas/Centro Universitário Federal -Efoa/Ceufe. Eles tiveram seu peso aferido e, a seguir, foram sedados com éter etílico e anestesiados com solução de xilazina e cetamina, na proporção de 1:1 e na dose de $0,2 \mathrm{ml} / 100 \mathrm{~g}$ de peso corpóreo, por via intraperitoneal. Depois de colocados em decúbito dorsal horizontal, a face ventral do abdome foi depilada manualmente e descontaminada com álcool a $70 \%$.

Com a finalidade de induzir a HI mediana, todos os animais foram submetidos a uma incisão transversa, suprapúbica, com 10mm de comprimento, realizada com bisturi, interessando a pele e a tela subcutânea, através da qual estes foram separados do plano muscular por dissecção romba, com tesoura, em direção cranial e a cada lado da linha mediana. A seguir, a linha alba e o peritônio parietal foram seccionados numa extensão de $30 \mathrm{~mm}$, mantendo-se íntegra a pele suprajacente. Apenas a ferida cutânea foi suturada com dois pontos de categute simples $5-0^{7}$.

No pós-operatório, os ratos de cada subgrupo foram mantidos em gaiolas para até cinco animais, com ração e água ad libitum e examinados, diariamente, para inspeção da ferida cirúrgica e constatação da HI, até o final de cada período de observação. Aqueles que morressem ou apresentassem complicações do sítio operado, que não a HI, seriam excluídos do experimento.

Em seguida, eles foram distribuídos em dois grupos de dez animais, de acordo com o período de observação. Cada grupo era constituído por cinco ratos, nos quais o ultra-som não foi aplicado 
(subgrupo controle), e cinco que receberam essa aplicação (subgrupo experimental). Os subgrupos foram definidos da seguinte forma:

- C 14 - controle de 14 dias;

- US 14 - aplicação de ultra-som por 14 dias;

- C 28 - controle de 28 dias;

- US 28 - aplicação de ultra-som por 28 dias.

No primeiro dia pós-operatório, iniciou-se a aplicação do US nos animais do grupo experimental. Um a um, eles foram apreendidos pelo dorso e envolvidos em tecido flanelado, deixando-se livre o abdome, para as aplicações do US. Nenhum procedimento anestésico ou de sedação foi empregado. Utilizou-se um aparelho da marca $\mathrm{KW}^{\circledR}$, de cabeçote reduzido ( $10 \mathrm{~mm}$ de diâmetro), na freqüência de $3,0 \mathrm{MHz}$, com intensidade de $0,5 \mathrm{~W} /$ $\mathrm{cm}^{2}$, em modo pulsado 1:5, massageando-se levemente toda a área operada (e especialmente a ferida cirúrgica), devidamente lubrificada com gel condutor, em movimentos circulares contínuos, durante cinco minutos. As sessões de US foram realizadas uma vez ao dia, até a data da eutanásia, inclusive.

Após 14 dias e 28 dias de induzida a HI, os animais foram submetidos à eutanásia por inalação de éter etílico. Após a remoção da pele e da tela subcutânea, foi seccionado um fragmento do estrato músculo-aponeurótico da parede abdominal, incluindo o peritônio, englobando toda a área da laparotomia. Nesse bloco, encontrava-se o tecido cicatricial ou a hérnia incisional, quando presente.

A mensuração dos diâmetros transversal e longitudinal do anel herniário ou da largura da cicatriz na linha alba, em milímetros, foi feita pela face peritoneal. Considerou-se a presença de HI, quando a medida transversal era maior que $2 \mathrm{~mm}$. Para os valores menores ou iguais a $2 \mathrm{~mm}$, definiu-se a estrutura como cicatriz na linha alba.

Os fragmentos obtidos da parede abdominal foram fixados em ALFAC (álcool a 80\% + formol a $40 \%$ + ácido acético glacial), na proporção de 8,5:1:2, durante 24 horas. Em seguida foram desidratados, diafanizados e incluídos em parafina. Os blocos foram cortados com $5 \mathrm{~mm}$ de espessura, envolvendo o saco herniário e a musculatura adjacente a ele. Três lâminas de cada animal foram coradas pela hematoxilina-eosina (HE), para uma descrição geral e estudo dos vasos sangüíneos e dos fibroblastos, e outras três pelo tricrômico de Gomori, para avaliação das fibras colágenas.

A quantificação dos achados histológicos foi determinada pela densidade das estruturas citadas, no saco herniário ou na cicatriz da linha alba, por meio de morfometria de contagem de pontos. Utilizou-se um microscópio óptico(Olympus ${ }^{\circledR}$ CBA), acoplado a uma câmera de vídeo (SV Micro Sound Vision $^{\circledR}$ ) e um retículo sobreposto à imagem do campo microscópico, projetada em monitor de 15 polegadas. Analisaram-se 15 campos aleatórios, para cada subgrupo, obtendo-se o valor médio dessas medidas. A área-teste do retículo foi de $0,0625 \mathrm{~mm}^{2}$, para a quantificação de vasos sanguíneos e fibroblastos (objetiva de x20); para as fibras colágenas, a áreateste do retículo foi de $0,0576 \mathrm{~mm}^{2}$ (objetiva de $\mathrm{x} 10$ ), uma vez que tais fibras são melhor observadas em aumentos menores.

A média e o erro padrão foram calculados para os dados quantitativos. Asignificância das diferenças observadas foi determinada por análise de variância (ANOVA) e teste de comparação múltipla de TukeyKramer, considerando-se $\mathrm{p} £ 0,05$ (INSTAT, GraphPad Software $^{\circledR}$ Inc. 1993).

O projeto foi aprovado pelo Comitê de Ética na Experimentação Animal da Efoa/Ceufe (protocolo 09/ 2002), onde este trabalho foi desenvolvido. O número de animais alocados por subgrupo seguiu as orientações do Comitê. Um experimento piloto foi realizado em três animais, para o treinamento da equipe no procedimento cirúrgico e na aplicação do US.

\section{Resultados}

Em todos os animais dos subgrupos controle, tanto de 14 dias como de 28 dias, a HI desenvolveuse nos primeiros dias de pós-operatórios, com anel e saco herniários bem configurados (Figuras 1A e 1B). Nos que receberam o US, seja por 14 dias seja por 28 dias, três dos cinco animais de cada subgrupo (60\%) não desenvolveram a HI, pois a largura da cicatriz na linha alba foi d"2mm (Figuras 2A e 2B). $\mathrm{O}$ valor médio das medidas do diâmetro transversal do anel herniário, nos subgrupos controle, não apresentou diferença significante. Naqueles em que o US foi aplicado, houve redução dessas medidas em relação aos controles, mas não entre si (análise de variância: 
$\mathrm{p}<0,0001)$. Com relação ao diâmetro longitudinal, ou do comprimento da cicatriz na linha alba, a média das medidas não diferiu estatisticamente, tanto nos ratos dos subgrupos controle quanto nos que receberam o US (Tabela 1 ).

À microscopia óptica, os fragmentos do estrato músculo-aponeurótico da parede abdominal, envolvendo a região operada, evidenciaram a presença de tecido conjuntivo denso, caracterizado por feixes de fibras colágenas, permeadas por vasos sangüíneos e células de núcleo alongado, com tecido muscular estriado adjacente. Nos animais que receberam o US, essa neoformação conjuntiva

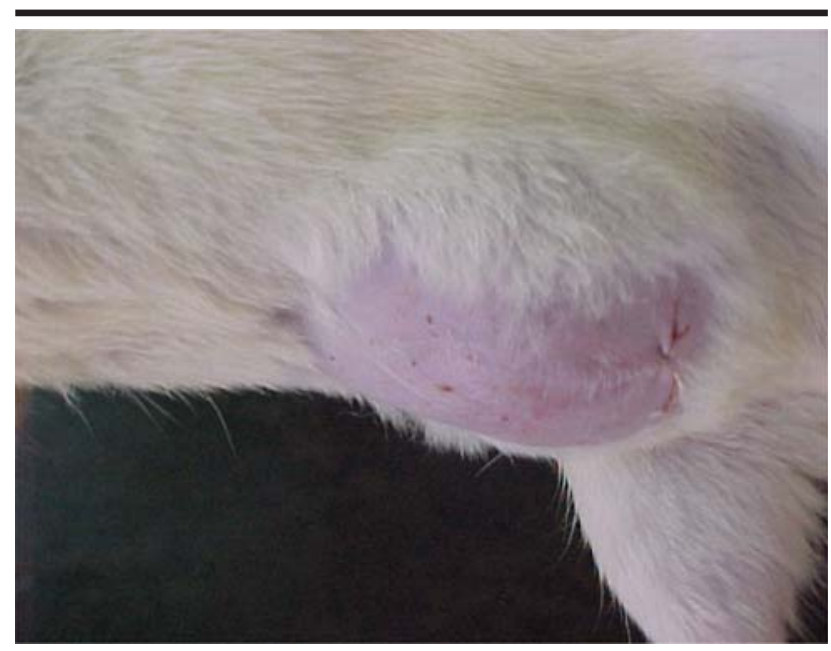

FIGURA 1A - Ectoscopia do rato do subgrupo controle de 28 dias, com hérnia incisional.

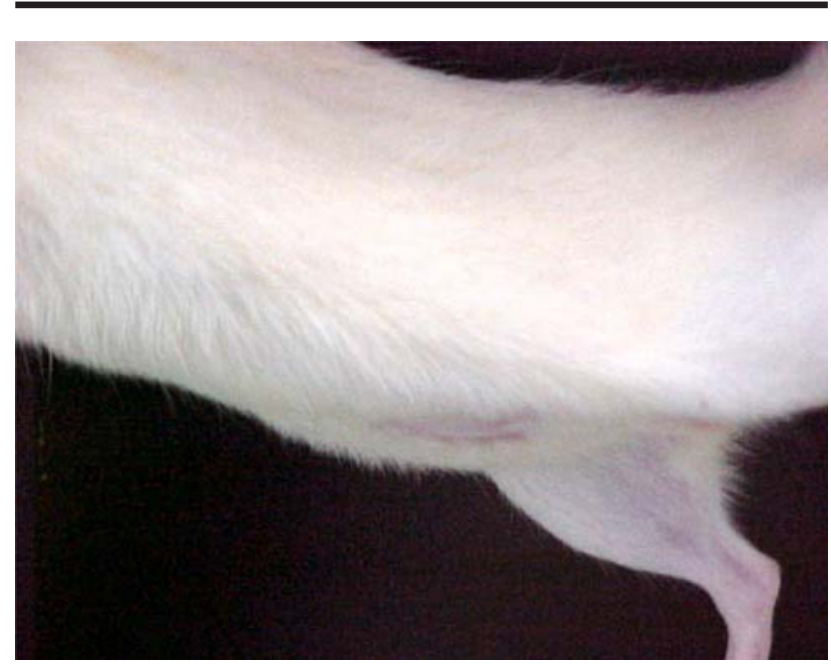

FIGURA 2A - Perfil do rato do subgrupo em que foi aplicado o ultra-som por 28 dias, sem hérnia incisional. configurou apenas uma cicatriz na linha alba ou um saco herniário menos desenvolvido. A coloração pelo tricrômico de Gomori permitiu confirmar a presença das fibras colágenas, que ficaram coradas em azul, em meio a células de tonalidade avermelhada e núcleo alongado (Figuras 3 e 4).

A análise de variância demonstrou o aumento significante na densidade de vasos sangüíneos $(\mathrm{p}=0,0031)$, de fibroblastos $(\mathrm{p}<0,0001)$ e de fibras colágenas $(\mathrm{p}=0,0015)$ nos animais que receberam o US por 14 dias, mas não aos 28 dias de aplicação do US, o que se confirmou pelo teste de comparação múltipla (Tabela 2).

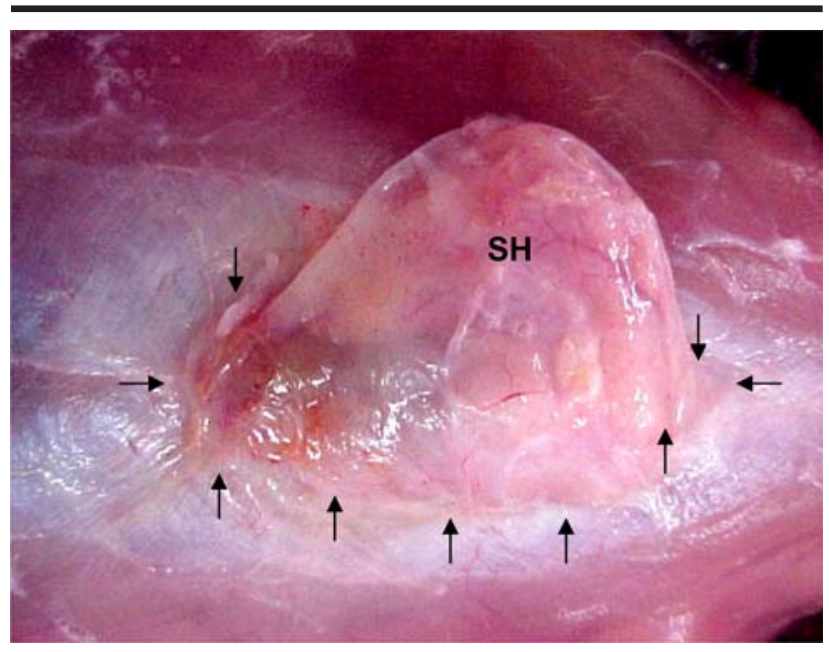

FIGURA 1B - Aspecto do estrato músculo-aponeurótico do mesmo animal, após a retirada da pele e da tela subcutânea, evidenciando-se o saco herniário (SH) e o anel (setas).

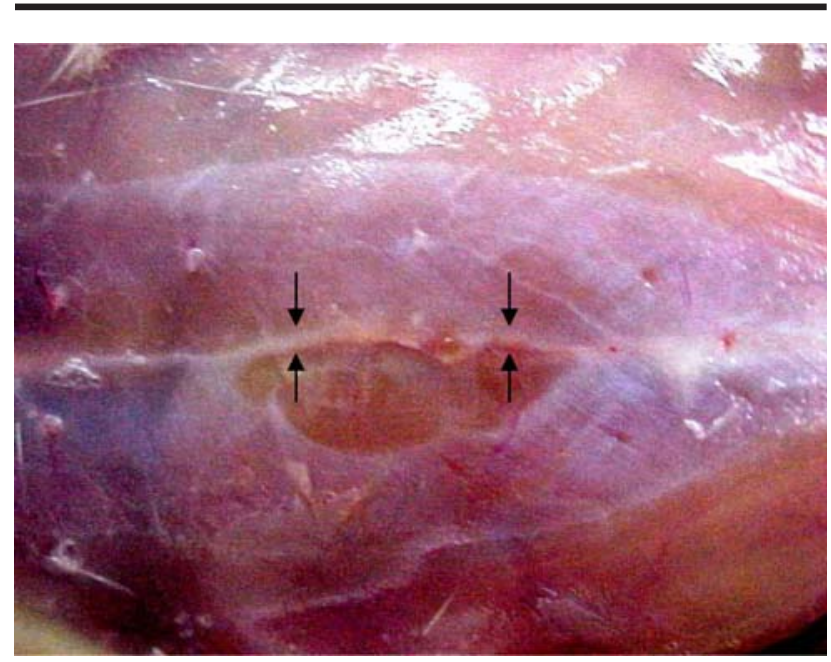

FIGURA 2B - Aspecto do estrato músculo-aponeurótico do mesmo animal, após a retirada da pele e da tela subcutânea, evidenciando-se a cicatriz na linha alba (setas). 


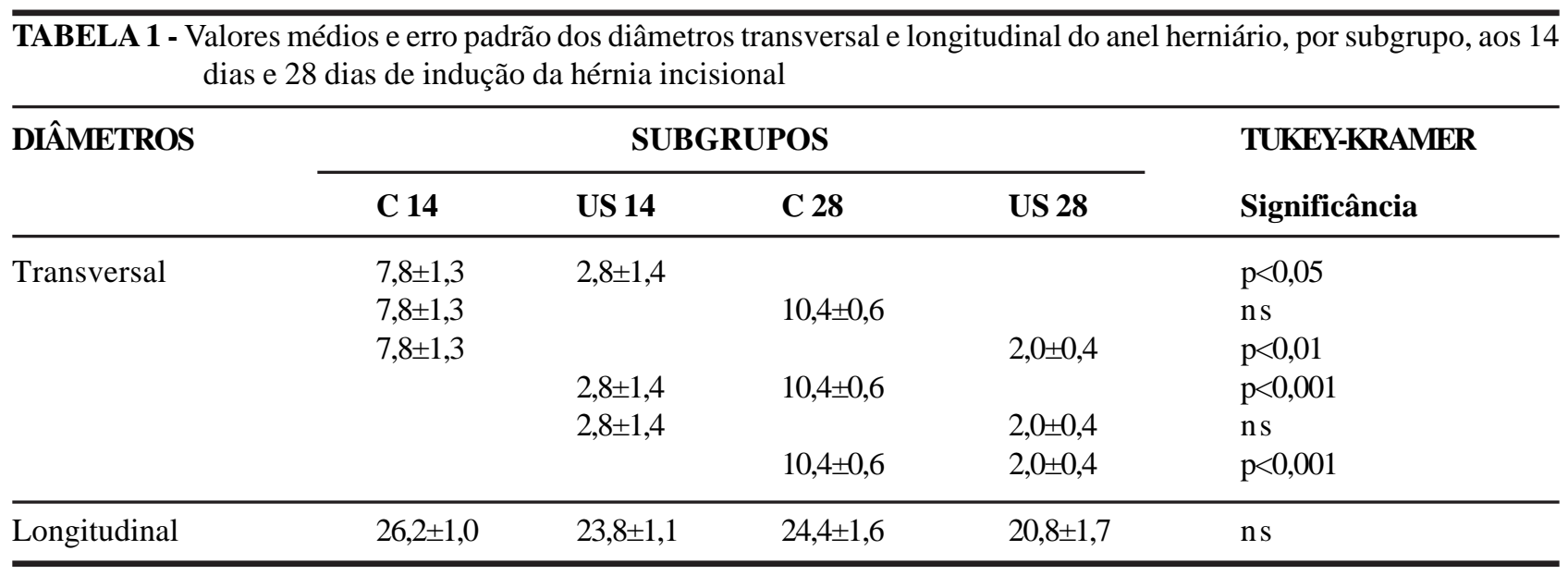

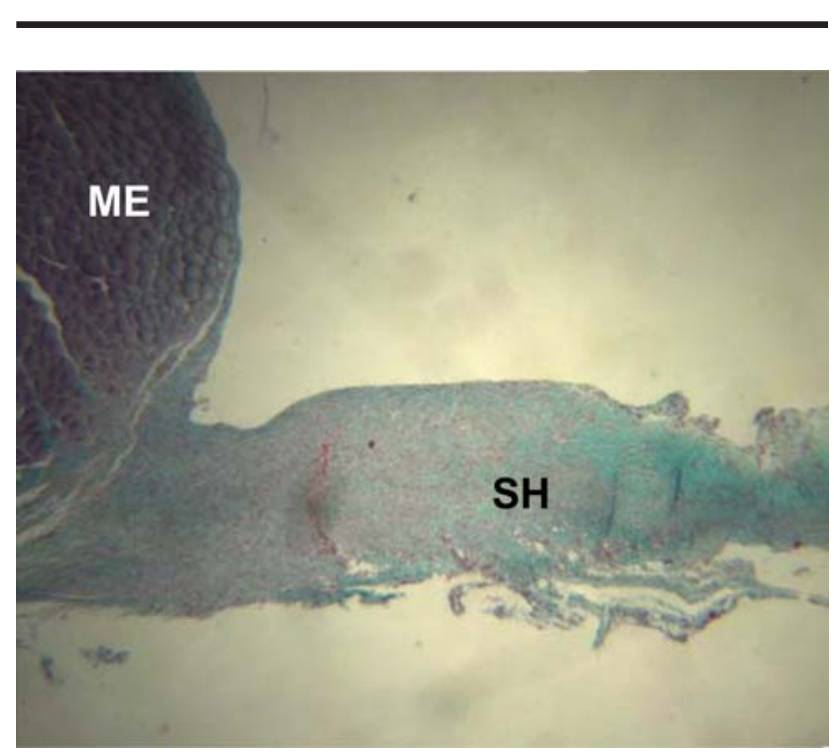

FIGURA 3 - Fotomicrografia do plano músculo-aponeurótico abdominal de rato (subgrupo controle de 28 dias), em que se vê parte do saco herniário (SH), com fibras colágenas, em azul, adjacente ao tecido muscular estriado (ME), em vermelho (objetiva de $\mathrm{x} 4$, Gomori).

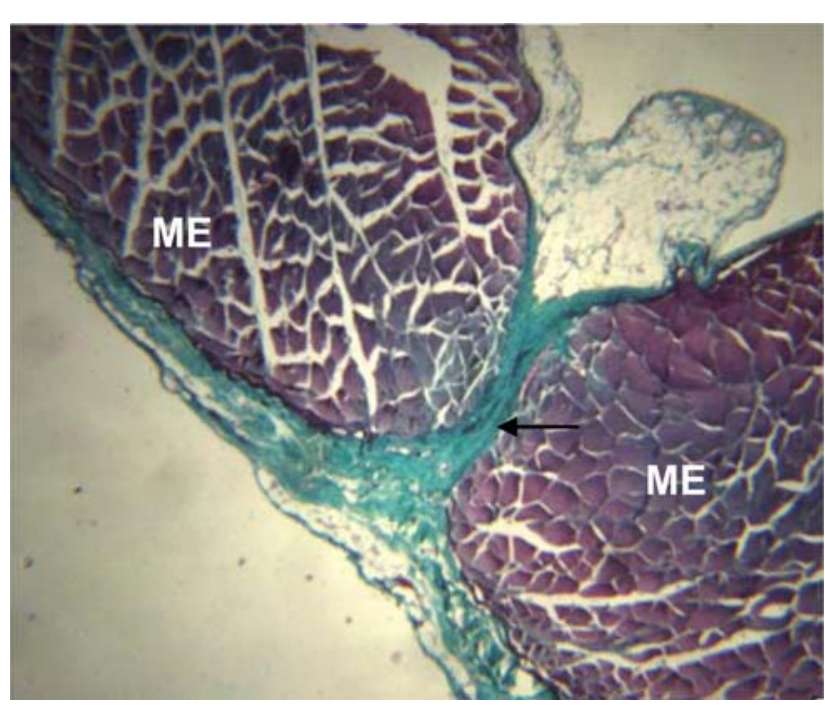

FIGURA 4 - Fotomicrografia do plano músculo-aponeurótico da parede abdominal de rato (subgrupo que recebeu o US por 28 dias), em que se vê a cicatriz na linha alba (seta), constituída por tecido conjuntivo denso, em azul, com o tecido muscular estriado (ME) a cada lado (objetiva de x4, Gomori). 
TABELA 2 - Valores médios e erro padrão, por subgrupo, da densidade de vasos sangüíneos, fibroblastos e fibras colágenas no saco herniário ou na cicatriz da linha alba.

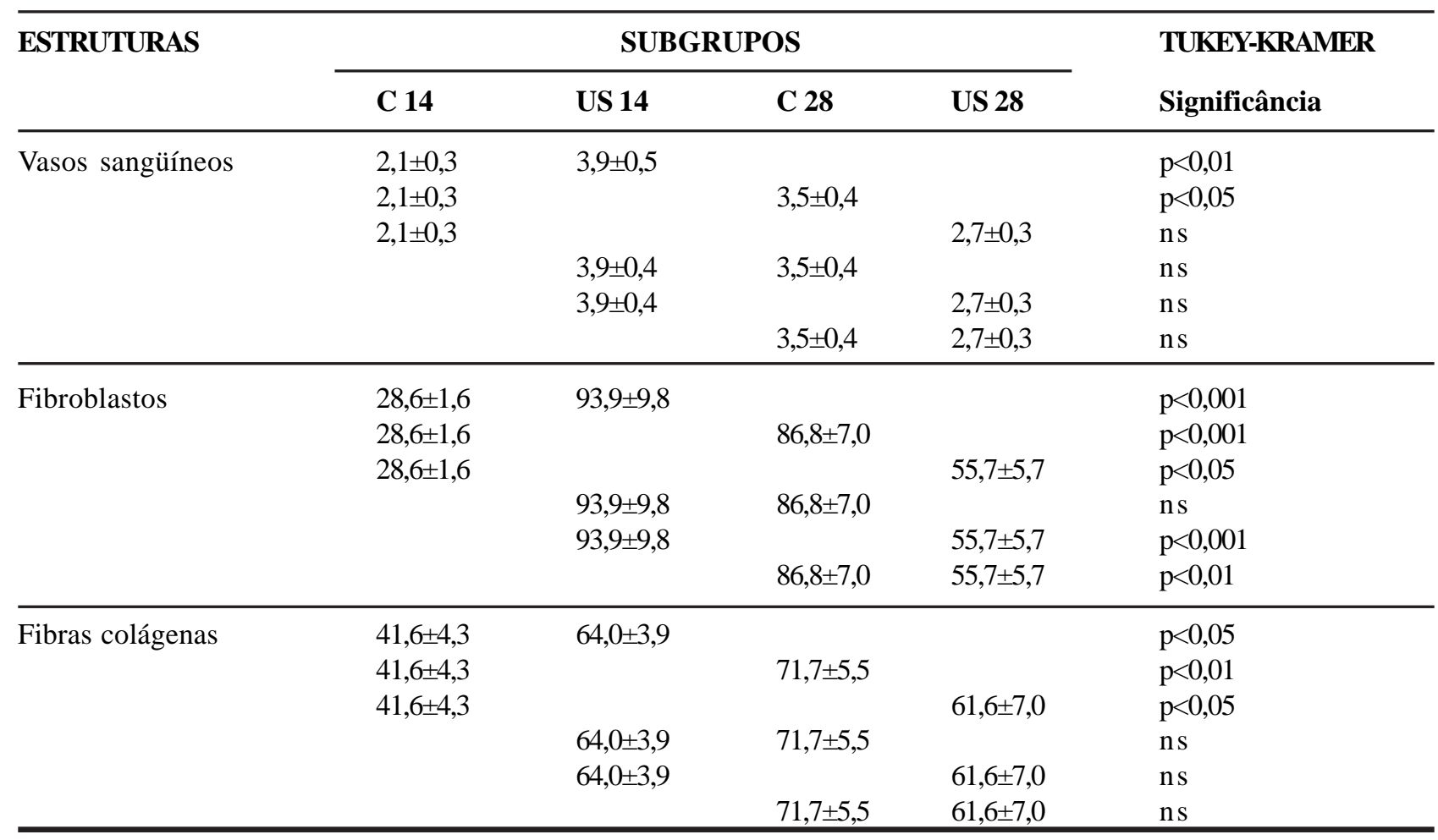

\section{Discussão}

A laparotomia mediana é a que mais freqüentemente se associa à HI, consistindo mesmo em fator de risco para o desenvolvimento dessa complicação. Ao se incisar a linha alba, ocorre a desinserção das aponeuroses dos músculos laterais do abdome (oblíquo externo, oblíquo interno e transverso), que ali decussam. Como resultado, as fibras desses músculos sofrem encurtamento, hipotrofia e degeneração gordurosa, sendo que as aponeuroses também se retraem, provocando o afastamento dos músculos retos do abdome. O equilíbrio de forças entre essa tração lateral e a resistência contraposta pela cicatriz na linha alba irá determinar o tamanho desse anel e, conseqüentemente, da HI. Valores iguais ou superiores a $10 \mathrm{~cm}$ de largura caracterizam as $\mathrm{HI}$ grandes, com aumento significante na sua morbidez. Figuram, também, como fatores de risco, a infecção do sítio cirúrgico, a obesidade (de todos, o mais consistente) e as alterações metabólicas do tecido conjuntivo. A pressão intra-abdominal, normalmente baixa, contribui muito pouco para a formação da HI, mas pode ser relevante na presença de ascite, seja a associada à insuficiência renal ou à hepática ${ }^{8-12}$.
As repercussões fisiopatológicas dessas hérnias outorgam-lhes o caráter de doença, e não o de um mero defeito parietal. O diafragma não mais encontra a resistência das vísceras, que se alojam no saco herniário (perda de domicílio). Com essa diminuição da pressão intra-abdominal, ele diminui suas incursões até hipotrofiar-se, o que, aliado ao enfraquecimento irreversível da parede abdominal (perda do efeitoprensa), reflete negativamente na mecânica ventilatória, na tonicidade das vísceras ocas, no retorno venoso e na postura. As aderências vísceroparietais ao saco herniário colaboram para a irredutibilidade do conteúdo herniado, além de favorecerem a obstrução intestinal. A trombose dos vasos da pele causa as distrofias e mesmo as úlceras cutâneas, que ficam localizadas no ápice da eventração ${ }^{8}$. A conseqüência dessas alterações equivale à incapacidade profissional, em graus variados, elevando ainda mais o custo social dessa doença. Por isso, todos os cuidados ao alcance do cirurgião devem ser tomados para o fechamento adequado das laparotomias, no sentido de se evitar a possibilidade de ocorrência da HI e de outras complicações ${ }^{2}$.

O modelo experimental, aqui adotado, foi eficaz ao reproduzir a HI conforme encontrado no pós- 
operatório de uma laparotomia mediana, diferente daquela produzida pela retirada de um fragmento músculo-aponeurótico da parede abdominal, que normalmente sucede às avulsões traumáticas e às cirurgias oncológicas, em que o tumor acomete primária ou secundariamente a parede. Em todos os animais dos subgrupos controle, tanto de 14 dias como de 28 dias, ela se desenvolveu já nos primeiros dias pós-operatórios, com seus elementos constitutivos (anel e saco herniários) bem configurados. Uma vez que não houve diferença significante entre as medidas do diâmetro transversal do anel herniário, nesses animais, pode-se afirmar que a HI atingiu sua estabilidade 14 dias após a sua indução.

Nos animais que receberam o US, essa aplicação foi capaz de prevenir o desenvolvimento da HI na maioria deles e, mesmo nos demais, a largura do anel herniário foi menor em relação aos controles. Clinicamente, é essa medida que define a ocorrência ou não da HI mediana, resultado da falência do processo reparativo (cicatricial), que provoca a diástase dos músculos retos do abdome. Não houve, entretanto, diferença entre tais medidas, comparandose a aplicação do US por 14 dias ou por 28 dias, sugerindo ser suficiente um período menor de utilização, desde que iniciada precocemente, isto é, ainda na fase inflamatória.

A cura de qualquer ferida passa, obrigatoriamente, pelos fenômenos de hemostasia e de reconstituição dos tecidos lesados (reparo). Este último é marcado por três etapas: a inflamação, a formação do tecido de granulação e a remodelação. Na primeira, predominam a vasodilatação e a diapedese dos leucócitos, que realizam a fagocitose das células mortas ou danificadas, dos coágulos e dos microrganismos contaminantes. Esse desbridamento biológico da ferida é garantido pelos neutrófilos e macrófagos principalmente. Em seguida, aparecem os fibroblastos, oriundos do tecido conjuntivo adjacente, sob a ação de fatores quimiotáticos e de crescimento, liberados pelas plaquetas e também pelos macrófagos. Com eles, têm início a síntese e a deposição dos elementos da matriz extracelular (fibroplasia) e a neoformação capilar (angiogênese), que irão constituir o tecido de granulação. Só então é que a ferida passa a apresentar resistência à tração (RT), proporcionalmente ao acúmulo de fibras colágenas. Após um certo período, que varia de tecido para tecido, essa quantidade de colágeno se estabiliza, graças à renovação das fibras velhas por novas. Apesar disso, a ferida continua ganhando RT, até alcançar um nível máximo (platô), cerca de $80 \%$ do tecido não lesado. Nessa fase, o que ocorre é a remodelação do tecido cicatricial, isto é, as fibras colágenas são reorientadas ou realinhadas nas direções de maior solicitação, a partir das forças de tração que atuam sobre a ferida, incrementando a sua RT, sem aumentar a quantidade de colágeno depositado na cicatriz. Durante essa terceira e última etapa do reparo, que nas aponeuroses pode estenderse por vários meses, o tecido de granulação, rico em vasos e células, transforma-se em uma massa rarefeita desses elementos, quando a maioria dos capilares e dos fibroblastos desaparece.

Sabe-se, atualmente, que as alterações do tecido conjuntivo que muitos pacientes com $\mathrm{HI}$ apresentam, referem-se, em última análise, à desproporção entre a quantidade do colágeno tipo 1 e 3 , que estaria anormalmente invertida nas fibras desses pacientes. Essa desproporção pode decorrer da destruição aumentada do primeiro tipo, a partir da ativação de metaloproteinases da matriz, ou por aumento anômalo da expressão gênica do segundo. A diminuição da síntese local de fatores de crescimento celular, as alterações nas moléculas de adesão entre os fibroblastos e as fibras colágenas e de outras moléculas da matriz também já foram demonstradas. Isso tem reflexos na resistência do conjuntivo como um todo, especialmente o das aponeuroses, diminuindo a sua RT e, conseqüentemente, o seu poder de sustentação ou de contenção da parede abdominal ${ }^{13}$.

A análise histométrica, tanto da cicatriz na linha alba quanto do saco herniário, mostrou o aumento significante na densidade de vasos sangüíneos, de fibroblastos e de fibras colágenas nos animais que receberam o US por 14 dias. Essas medidas tenderam ao declínio, ao final do período estudado, seguindo exatamente o encadeamento habitual dos fenômenos reparativos.

Entre os fibroblastos, muitas das células apresentavam características morfológicas e tintoriais em tudo semelhantes às das fibras musculares lisas (FML), encontradas na parede dos vasos sangüíneos. Embora não tenha sido prevista no método, buscouse a confirmação deste achado por imunohistoquímica, utilizando-se anticorpo anti-actina a, 
para identificação de músculo liso. Qualitativamente, a grande maioria dessas células expressou a actina no citoplasma. Trata-se, provavelmente, de miofibroblastos e/ou de outro(s) derivado(s) do fibroblasto, entre eles as próprias FML, cuja diferenciação ainda não se completou nos períodos de observação adotados neste ensaio. Uma investigação dessas células, assim como de fatores de crescimento (TGF b), utilizando-se o modelo experimental, aqui adotado, já está sendo especificamente elaborado pelo nosso grupo.

A despeito do aprimoramento dos materiais com os quais as próteses são confeccionadas, dos avanços nas áreas de fisioterapia, de anestesiologia, de medicina intensiva e, evidentemente, das técnicas e táticas cirúrgicas, parece que a ocorrência de HI tem se mantido expressiva, em decorrência do número crescente de cirurgias de maior porte, realizadas em pacientes cada vez mais graves ou idosos. Mesmo a cirurgia videolaparoscópica(CVL), mininvasiva por excelência, atesta que essa complicação não desapareceu do cenário cirúrgico, com a ocorrência das hérnias nos portais para os trocartes. Justificase, portanto, o emprego de medidas que previnam ou, então, minimizem a magnitude desse problema, além dos cuidados técnicos na realização da abertura e do fechamento das feridas abdominais, já referidos.

A eletroestimulação por corrente retangular, pulsada, simétrica, bipolar, de baixa freqüência, apesar de ter-se mostrado eficaz em estudos experimentais de $\mathrm{HI}^{14}$, ainda não foi investigada, clínica ou experimentalmente, em nosso meio, para aplicação em pacientes portadores dessa doença.

A utilização dos fatores de crescimento celular, para injeção na ferida operatória, seja em pacientes submetidos a uma laparotomia ou ao reparo de uma HI, já instalada, também é efetiva nesses casos ${ }^{15}$. Tais substâncias, para administração direta no sítio cirúrgico, ainda não estão disponíveis para uso em seres humanos e, talvez também por onerar muito tais procedimentos, ainda não têm aplicação clínica estabelecida.

O US é um equipamento usualmente encontrado nas clínicas de fisioterapia e com ampla utilização no tratamento das lesões músculo-tendíneas, nas quais as HI estão inseridas. De acordo com os resultados deste trabalho, ele mostrou-se efetivo na prevenção da HI experimental, uma vez que sua ação estimulou o reparo tecidual. Complementar às técnicas atuais de reparo das HI, com ou sem prótese, o US pode ser útil como terapia adjuvante, indicada também no pós-operatório de pacientes submetidos a uma laparotomia, com risco aumentado para o desenvolvimento dessa complicação (via de acesso mediana, obesidade, contaminação do campo cirúrgico, entre outros), apesar do cuidado de se extrapolar resultados obtidos em animais de laboratório para seres humanos. Seus efeitos colaterais são desprezíveis, uma vez obedecidos os princípios básicos para sua aplicação. Além disso, o custo de obtenção do equipamento, sendo baixo, desonera o tratamento, tornando-o acessível à maioria desses pacientes ${ }^{6}$. Outros trabalhos devem ser levados a termo, para definir melhor as doses e os períodos de aplicação do US, utilizando-se não só modelos de HI primária, mas também após o seu reparo cirúrgico.

\section{Conclusão}

O ultra-som evitou o aparecimento da $\mathrm{HI}$ ou reduziu o seu tamanho, quando aplicado por 14 dias no pós-operatórios.

\section{Referências}

1. Losanoff JE, Richman BW, Jones JW. Enterocolocutaneous fistula: a late consequence of polypropylene mesh abdominal wall repair: case report and review of the literature. Hernia. 2002;6:144-7.

2. Hodgson NC, Malthaner RA, Ostbye T. The search for an ideal method of abdominal fascial closure: a metaanalysis. Ann Surg. 2000; 231:436-42.

3. van't Riet M, Steyerberg EW, Nellensteyn J, Bonjer HJ, Jeekel J. Meta-analysis of techniques for closure of midline abdominal incisions. Br J Surg. 2002;89:1350-6.

4. Gouvêa CMCP, Vieira PMN, Amaral AC. Efeito do ultrasom na recuperação de músculo tibial anterior de rato lesado. Rev Univ Alfenas. 1998;4:165-73.

5. Rantanen J, Thorsson O, Wollmer P, Hurme T, Kalimo H. Effects of therapeutic ultrasound on the regeneration of skeletal myofibers after experimental muscle injury. Am J Sports Med. 1999;27:54-9.

6. Low J, Reed A. Ultra-som terapêutico. In: Eletroterapia explicada: princípios e prática. 3ed. Barueri: Manole; 2001. p.187-228.

7. Paulo DNS, Fausto ELP, Ricardo FM, Dauad FR, Paulo ICAL. Experimental models of longitudinal abdominal incisional hernia in rats. Acta Cir Bras. 1997;12:231-4.

8. Flament JB, Rives J, Palot JP, Burde A, Avisse C. Major incisional hernia. In: Chevrel JP, editor. Hernias and surgery of the abdominal wall. 2ed. Berlin: Springer- 
Verlag; 1998. p.128-58

9. Luijendijk RW, Hop WCJ, Tol P, Lange DCD, Braaksma MMJ, Ijzermans JNM et al. A comparison of suture repair with mesh repair for incisional hernia. N Engl J Med. 2000;343:392-8.

10. Korenkov M, Paul A, Sauerland S, Neugebauer E, Arndt $\mathrm{M}$, Chevrel JP et al. Classification and surgical treatment of incisional hernia: results of an expert's meeting. Langenbecks Arch Surg. 2001;386:65-73.

11. Grantcharov TP, Rosenberg J. Vertical compared with transverse incisions in abdominal surgery. Eur J Surg. 2001;167:260-7.

12. O’Dwyer PJ, Courtney CA. Factors involved in abdominal wall closure and subsequent incisional hernia.
Surg J R Coll Surg Edinb Irel. 2003;1:17-22.

13. Rosch R, Junge K, Knops M, Lynen P, Klinge U, Schumpelick V. Analysis of collagen-interacting proteins in patients with incisional hernias. Langenbecks Arch Surg. 2003;387:427-32.

14. Franke A, Reeding R, Tessmann D. Electrostimulation of healing incisional hernias by low frequency, bipolar, symmetrical rectangular pulses: an experimental study. Acta Chir Scand. 1990;156:701-5.

15. Franz MG, Kuhn MA, Nguyen K, Wang X, Ko F, Wright TE, Robson MC. Transforming growth factor $b_{2}$ lowers the incidence of incisional hernias. J Surg Res. 2001;97:109-16.
Correspondência:

Alcino Lázaro da Silva

Rua Guaratinga, 151

30315-430 Belo Horizonte-MG

Tel.: (31) 3273-0491
Conflito de interesse: nenhum Fonte de financiamento: nenhuma

Recebimento: 26/09/2004

Revisão: 03/11/2004

Aprovação: 19/12/2004

\section{Como citar este artigo:}

Melo RM, Gouvêa CMCP, Silva AL. Efeito do ultra-som na prevenção da hérnia incisional mediana no rato. Acta Cir Bras. [serial online] 2005 Jan-Fev;20(1). Disponível em URL: http://www.scielo.br/acb

*Figuras coloridas disponíveis em www.scielo.br/acb 